\title{
Peripheral gangrene in hypernatraemic dehydration of infancy
}

\author{
S. C. COMAY and C. D. KARABUS \\ From the Department of Paediatrics and Child Health, University of Cape Town, and Red Cross \\ War Memorial Children's Hospital, Rondebosch, Cape, South Africa
}

\begin{abstract}
Comay, S. C., and Karabus, C. D. (1975). Archives of Disease in Childhood, 50, 616. Peripheral gangrene in hypernatraemic dehydration of infancy. Gangrene of the extremities complicating diarrhoea and severe hypernatraemic dehydration occurred in 6 infants. This is a rare complication of gastroenteritis, and its association with hypernatraemia does not seem to have previously been emphasized. The increased blood viscosity resulting from serum hyperosmolarity may have been responsible for the gangrene, and studies in our patients suggested that disseminated intravascular coagulation was present. In addition to fluid and electrolyte replacement, the infants were treated with heparin with some recovery of the affected extremities.
\end{abstract}

Sporadic case reports of peripheral gangrene associated with diarrhoea and dehydration in neonates and infants have appeared in recent years (Manios, Kanakoudi, and Miliaras-Vlachakis, 1972; Shehadi, Slim, and Dabbous, 1968; Smith et al., 1965; Nabseth and Jones, 1963; Bowie, McKenzie, and Hansen, 1958). Several causative factors for this complication have been suggested. They include Esch. coli endotoxin triggering disseminated intravascular coagulation (DIC) (Manios et al., 1972), femoral venepuncture (Nabseth and Jones, 1963), other needle trauma, purpura fulminans, thrombotic thrombocytopenic purpura, or an increase in blood viscosity due to dehydration (Shehadi et al., 1968). When recorded, the serum sodium concentration in these infants has invariably been in the hypernatraemic range $(>160 \mathrm{mEq} / \mathrm{l})$, though the association between gangrene and hypernatraemia does not appear to have been noted before.

Six infants with peripheral gangrene and dehydration are described here. All the infants had raised serum sodium concentration and studies suggested the additional presence of DIC.

\section{Patients}

During the period 1970-73, 36000 dehydrated children were admitted to this hospital for parenteral

Received 13 January 1975. fluid replacement. Gangrene of the extremities was present in $\mathbf{8}$ of these children.

\section{Clinical features.}

Case 1. A 5-month-old male had a 2-day history of diarrhoea and cough. He weighed $6 \mathrm{~kg}$, and was $5 \%$ dehydrated. His left foot was deeply cyanosed and cold, as was the distal portion of the right foot. Peripheral pulses below the femoral arteries were impalpable. He developed persistent convulsions the following day. The right foot recovered completely overnight but the left remained gangrenous and he eventually required amputation through the subtalar joint.

Case 2. A 9-month-old male had a 3-day history of diarrhoea and vomiting. He was $10 \%$ dehydrated and weighed $4.8 \mathrm{~kg}$. He had cyanosis of all the fingertips of the left hand and of the right middle and ring fingers (Fig. 1). All peripheral pulses were palpable. The right hand recovered fully after 3 weeks but 2 of the affected fingertips on the left side later underwent autoamputation.

Case 3. A one-year-old male weighing $9 \cdot 7 \mathrm{~kg}$ had diarrhoea for 3 days. He was severely dehydrated, irritable, hypertonic, and had cyanosis of the left ring finger and of all his toes. The following day the colour of his feet had improved, bullae formed on the finger and 2 toes, but subsequently only the fingertip became gangrenous.

Case 4. An 11-week-old female weighing $3.12 \mathrm{~kg}$ had been vomiting and passing loose stools for 3 days. She was $10 \%$ dehydrated, jittery, and had cyanosis of 


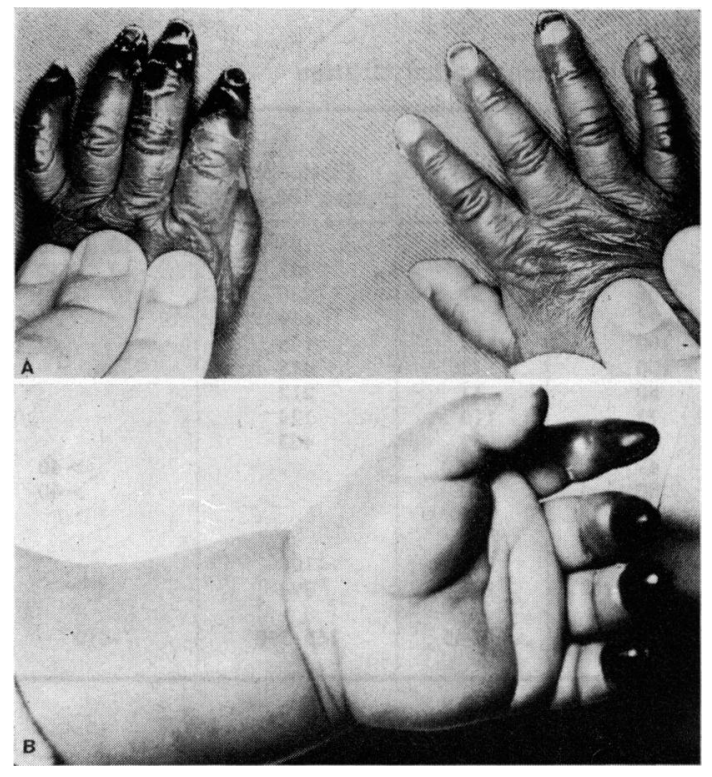

Fig. 1.-Case 2. (a) Gangrene of the fingertips of both hands involving $(b)$ all fingers on the left.

both feet (Fig. 2). The left foot recovered completely overnight but the toes of the right foot became gangrenous.

Case 5. An 8-month-old female had a 4-day history of diarrhoea; she weighed $5 \cdot 20 \mathrm{~kg}$, was severely dehydrated, and had cyanosis of both feet. Pedal pulses were impalpable. By the following day only the left foot was cyanosed (Fig. 3) but she had developed persistent convulsions. A bulla formed on the dorsum of the left foot. This sloughed later to reveal underlying normal skin and foot.

Case 6. A 5-month-old female weighing $7 \mathrm{~kg}$ was severely dehydrated following gastroenteritis. After rehydration she developed convulsions, and dark blue

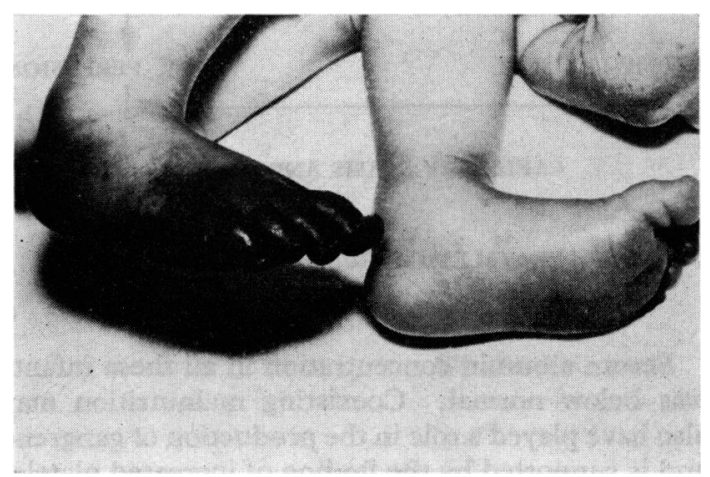

Fig. 2.-Case 4. Cyanosis of the feet.

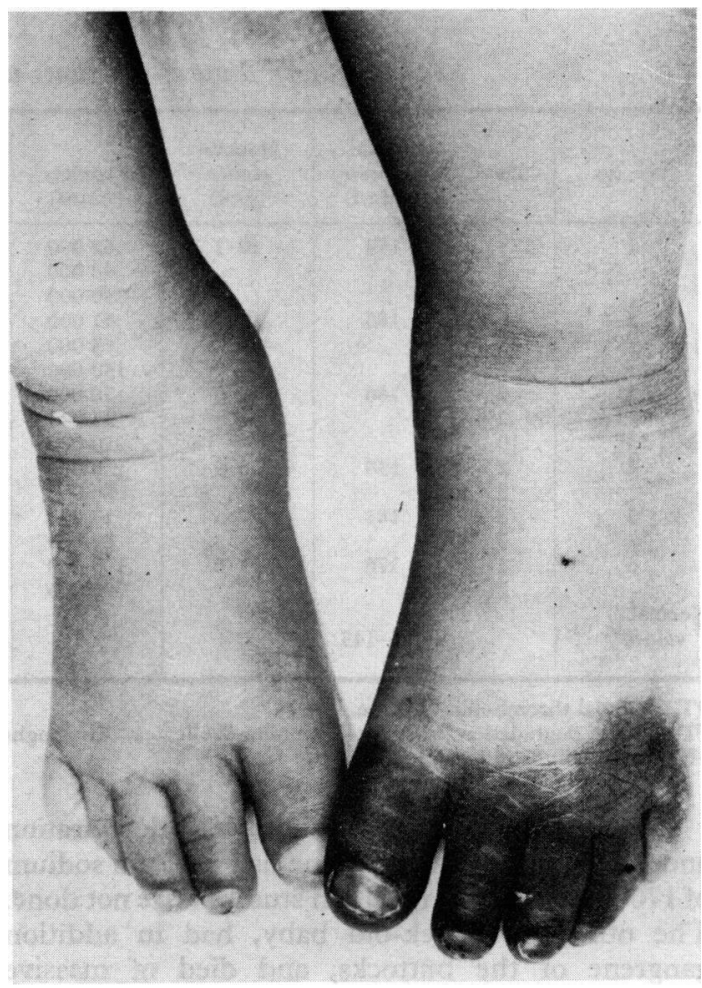

Fig. 3.-Case 5. Cyanosis of the left foot.

discoloration of all the toes on both feet was noted. The tips of 2 toes remained gangrenous.

Treatment. The infants were rehydrated intravenously with half-strength Darrow's solution in $2.5 \%$ dextrose water, and sodium bicarbonate was added to correct the acidosis. All except one (Case 4) received intravenous heparin 100 units/kg body weight 6 hourly. A low molecular weight dextran solution was given to one infant (Case 1). All received antibiotics.

\section{Results (Table)}

All the infants were hypernatraemic and had severe metabolic acidosis. The serum albumin concentration ranged from 1.8 to $3 \mathrm{~g} / 100 \mathrm{ml}$. Some of the infants were anaemic, the blood smear in 2 showing fragmented and burr cells. Reticulocyte counts when done were normal. A coagulation profile revealed abnormalities in all the infants, though complete laboratory data were not obtained in all cases. Haematological investigations were done by standard methods (Dacie and Lewis, 1968). Bacterial cultures of stool and blood were all negative. 
TABLE

Laboratory data of 6 infants with gangrene following dehydration

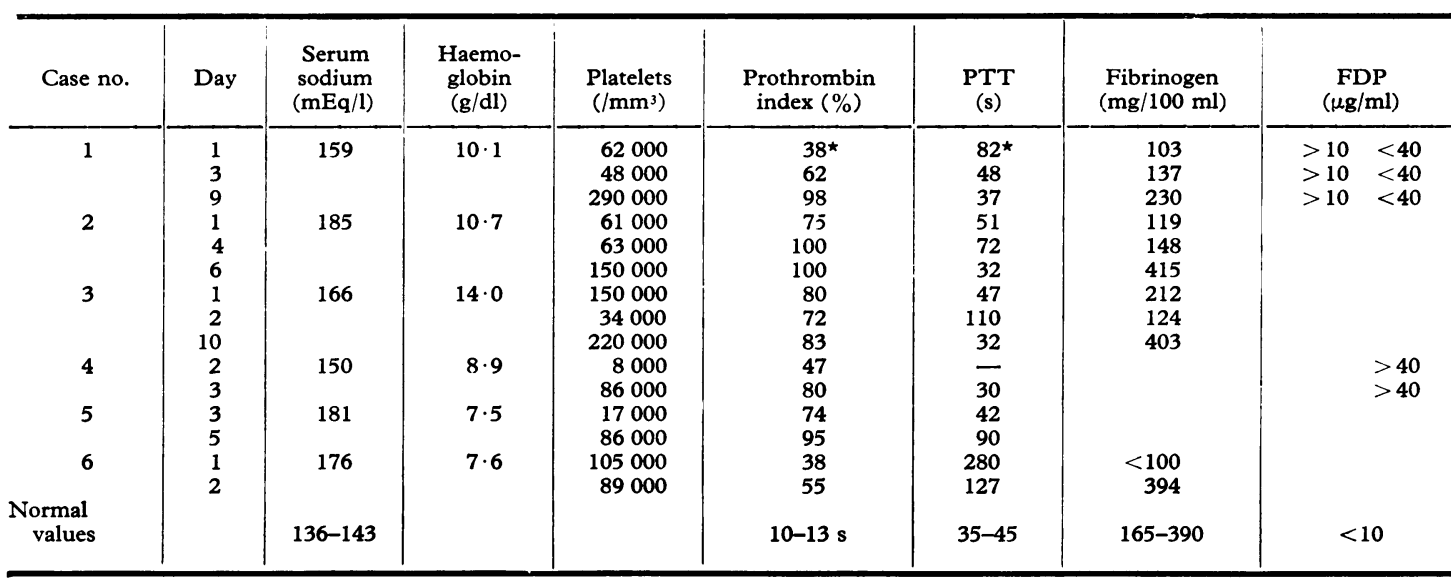

PTT, partial thromboplastin time.

FDP, fibrin degradation products (Thrombo-Wellcotest, Burroughs Wellcome).

$\star$ Factor assays: V $38 \%$, VIII $170 \%$.

Other cases. 2 other infants with dehydration and gangrene were seen. One had a serum sodium of $170 \mathrm{mEq} / 1$, but coagulation studies were not done. The other, a 5-week-old baby, had in addition gangrene of the buttocks, and died of massive pulmonary haemorrhage. Serum sodium 24 hours after admission and after rehydration, was 124 $\mathrm{mEq} / \mathrm{l}$, platelet count $35000 / \mathrm{mm}^{3}$, and prothrombin index $71 \%$.

\section{Discussion}

Peripheral gangrene is a rare complication of severe dehydration, occurring in only $8(0.02 \%)$ of 36000 children admitted to this hospital for parenteral fluid replacement. The association of gangrene and hypernatraemia appears to be a significant one as 7 of the 8 patients had hypernatraemic dehydration. Only $6 \%$ of patients with dehydrating gastroenteritis seen at this hospital had hypernatraemia (Beatty et al., 1974). This lends additional weight to the suggestion that the raised serum sodium concentration may have played a role in the production of gangrene in our cases.

Serum hypertonicity is known to increase blood viscosity (Meiselman et al., 1967; Rasmussen, 1972; Ham et al., 1968). Due to osmotic differences water passes from the red cells into the plasma, resulting in shrinkage and increased rigidity of erythrocytes (Rasmussen, 1972). In addition, acidosis (Rand et al., 1968) and hypoxia (La Celle and Weed, 1971) also reduce red cell deformability. As considerable erythrocyte deformation is required for blood flow through capillaries (Wells, 1970) these changes lead to an extremely high blood viscosity in the microcirculation (Ditenfass, 1968). Capillary stasis results in further localized hypoxia and acidosis rendering the blood hypercoagulable and causing endothelial injury with activation of factor XII and DIC (Hardaway, 1966). Alternatively, a damaged endothelial surface may predispose to platelet consumption only (Harker and Slichter 1972). Our patients all had thrombocytopenia together with changes suggesting DIC. The following scheme for initiation of DIC is proposed.

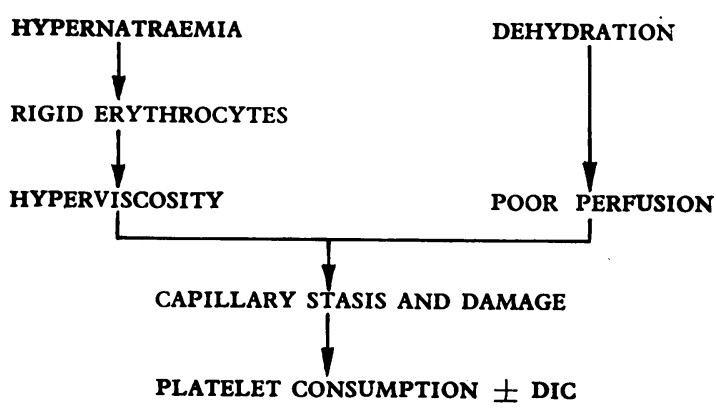

Serum albumin concentration in all these infants was below normal. Coexisting malnutrition may also have played a role in the production of gangrene and is supported by the finding of increased platelet adhesiveness in kwashiorkor (Khalil et al., 1974) and 
the fact that blood is hypercoagulable in fasted animals (Antoniades et al., 1973).

Signs referable to the central nervous system are frequently observed in hypernatraemic dehydration (Finberg, 1969), and these occurred in our patients. Cerebral haemorrhage may result from brain shrinkage, cerebral oedema may follow rapid rehydration (Finberg, 1969), and cerebral thromboses are occasionally found (Bowie et al., 1958). But even without these derangements, features of cerebral dysfunction are found. We propose that stasis of blood flow may occur in the cerebral microcirculation in hypernatraemia causing anoxia and cerebral dysfunction, as has been reported in newborn babies with increased blood viscosity due to polycythaemia (Gross, Hathaway, and McGaughey, 1973; Mackintosh and Walker, 1973).

Therapy of disseminated intravascular coagulation should be directed primarily towards eliminating the cause (Abilgaard, 1969). In gangrene following dehydration this implies replacement of the fluid and electrolyte deficit, and correction of acidosis and hypoxia. In view of the rapid recovery of the cyanosed extremities, clearing within hours in some cases, this therapy alone may be sufficient. Heparin was used as an anticoagulant in 5 of our infants and has been recommended in the presence of DIC when loss of one or more toes or other parts of the body is threatened by gangrene (Manios et al., 1972), but it was of doubtful value in the present series. Protection of the affected parts, strict asepsis and antiseptic cleansing, and cooling to decrease the metabolic demand of those tissues are suggested (Smith et al., 1965). Amputation may be necessary because of infection or impending autoamputation. Drugs interfering with platelet function (dipyridamole, acetylsalicyclic acid), or activators of fibrinolysis (streptokinase, urokinase) may be valuable but do not appear to have been used in this condition.

Reversal of impending gangrene occurred to some extent in all our patients, but in 4 of the infants loss of the distal portion of digits occurred and one patient required subtalar amputation of a foot. Further investigation is needed to elucidate the exact cause of gangrene in these cases as well as the role of hyperviscosity and disseminated intravascular coagulation in hypernatraemic dehydration.

\section{REFERENCES}

Abilgaard, C. F. (1969). Recognition and treatment of intravascular coagulation. Fournal of Pediatrics, 74, 163.
Antoniades, H. N., Iatrides, P. G., Westmoreland, N., Simon, J. D., Hayes, K. C., and Surgenor, D. M. (1973). Effects of nutritional, endocrine and metabolic state on the development of vascular coagulation induced by human serum preparations with procoagulant activity. Thrombosis et Diathesis Haemorrhagica, 29, 33.

Beatty, D. W., Mann, M. D., Heese, H. de V., and Berger, G. M. B. (1974). Acute dehydrating gastroenteritis in undernourished infants. South African Medical fournal, 48, 1563.

Bowie, M. D., McKenzie, D., and Hansen, J. D. L. (1958). Hyperosmolarity in infantile gastroenteritis. South African Medical fournal, 32, 322.

Dacie, J. V., and Lewis, S. M. (1968). Practical Haematology 4th ed. Churchill, London.

Ditenfass, L. (1968). Blood viscosity, internal fluidity of the red cell, dynamic coagulation and the critical capillary radius as factors in the physiology and pathology of circulation and microcirculation. Medical fournal of Australia, 1, 688.

Finberg, L. (1969). Hypernatremic dehydration. Advances in Pediatrics, Vol. 16, p. 325. Year Book Medical Publishers, Chicago.

Gross, G. P., Hathaway, W. E., and McGaughey, H. R. (1973). Hyperviscosity in the neonate. Fournal of Pediatrics, 82, 1004 .

Ham, T. H., Dunn, R. F., Sayre, R. W., and Murphy, J. R. (1968). Physical properties of red cells as related to effects in vivo. Blood, 32, 847.

Hardaway, R. M. (1966). Syndromes of Disseminated Intravascular Coagulation with Special Reference to Shock and Haemorrhage. Thomas, Springfield, Illinois.

Harker, L. A., and Slichter, S. J. (1972). Platelet and fibrinogen consumption in man. New England fournal of Medicine, 287, 999.

Khalil, M., Aref, M. K., Mahmoud, S., Abdel-Malek, A. T., Guirgis, F. K., Moghazy, M., and Abdel-Hay, M. M. (1974). Platelet adhesiveness, plasma free fatty acids, and serum triglycerides in kwashiorkor. Archives of Disease in Childhood $49,568$.

La Celle, P. L., and Weed, R. I. (1971). The contribution of normal and pathologic erythrocytes to blood rheology. Progress in Hematology, 7. 1.

Mackintosh, T. F., and Walker, C. H. M. (1973). Blood viscosity in the newborn. Archives of Disease in Childhood, 48, 547.

Manios, S. G., Kanakoudi, F., and Miliaras-Vlachakis, M. (1972). Gangrene of lower extremities in a newborn infant associated with intravascular coagulation. Helvetica Paediatrica Acta, 27, 187.

Meiselman, H. J., Merrill, E. W., Gilliland, E. R., Pelletier, G. A., and Salzman, E. W. (1967). Influence of plasma osmolarity on the rheology of human blood. Fournal of Applied Physio$\log y, 22,772$.

Nabseth, D. C., and Jones, J. E. (1963). Gangrene of the lower extremities of infants after femoral venipuncture. New England Fournal of Medicine, 268, 1003.

Rand, P. W., Austin, W. H., Lacombe, E., and Barker, N. (1968). pH and blood viscosity. Fournal of Applied Physiology, 25, 550.

Rasmussen, S. N. (1972). Influence of plasma hypertonicity on blood viscosity studied in vitro and in an isolated vascular bed. Acta Physiologica Scandinavica, 84, 472.

Shehadi, S. I., Slim, M. S., and Dabbous, I. A. (1968). Gangrene of lower extremities in infants following acute gastroenteritis. Plastic and Reconstructive Surgery, 42, 530.

Smith, J. W., Currarino, G., Golberg, H. P., and Conway, H. (1965). Gangrene of the extremities in the newborn and infant. American fournal of Surgery, 109, 306.

Wells, R. (1970). Syndromes of hyperviscosity. New England Fournal of Medicine, 283, 183.

Correspondence to Dr. C. D. Karabus, Red Cross War Memorial Children's Hospital, Rondebosch 7700, Republic of South Africa. 